\title{
Acoustic Emission and Vibration for Tool Wear Monitoring in Single-Point Machining Using Belief network
}

\author{
A.Prateepasen ${ }^{* * *}$, Y.H.J.Au ${ }^{* *}$, B.E. Jones ${ }^{* *}$ \\ * King Mongkut's University of Technology Thonburi, Bangmod, \\ Toong-kru, Bangkok, Thailand \\ Phone (662) 4709678 \\ Email: iasaasen@kmutt.ac.th \\ ** The Brunel Centre for Manufacturing Metrology, \\ Brunel University, Uxbride, Middlesex UB8 3PH \\ Phone (044-1895) 274000 \\ Email: joe.au@brunel.ac.uk
}

\begin{abstract}
This paper proposes an implementation of calibrated acoustic emission $(A E)$ and vibration techniques to monitor progressive stages of flank wear on carbide tool tips. Three cutting conditions were used on workpiece material, type EN24T, in turning operation. The root-mean-square value of $A E$ (AErms) and the coherence function between the acceleration signals at the tool tip in the tangential and feed directions was studied. Three features were identified to be sensitive to tool wear: AErms, coherence function in the frequency ranges $2.5-5.5 \mathrm{kHz}$ and $18-25 \mathrm{kHz}$. Belief network based on Bayes' rule was used to integrate information in order to recognise the occurrence of worn tool. The three features obtained from the three cutting conditions and machine time were used to train the network. The set of feature vectors for worn tools was divided into two equal sub-sets: one to train the network and the other to test it. The AErms in term of $A E$ pressure equivalent was used to train and test the net work to validate the calibrated acoustic. The overall success rate of the network in detecting a worn tool was high with low error rate.
\end{abstract}

Keywords- Acoustic emission, Vibration, Tool wear monitoring, Belief network.

\section{INTRODUCTION}

In machining, whether a tool needs to be changed is decided either by a machine operator or by the life expectancy of the tool. The judgement of the machine operator is often based on the visual inspection of the tool and the surface finish produced on the work piece, both requiring a certain degree of skill.

The decision based on tool-life expectancy suggests the idea of an average life for a class of tools calculated from previous data. For a particular machining condition, the tool manufacturer gives a recommended tool life for a given insert. This practice of tool replacement based on fixed tool life may not be the most economical since a tool can be replaced prematurely or only after damage has been done. Consequently, besides the unnecessary wastage of some tools, the frequent tool changes cause higher machine downtime, decreasing thereby the system productivity and increasing production costs.

In manufacturing, cutting cost and improving product quality are the necessary measures to adopt in an increasingly competitive world. In addition to the developments within manufacturing technology leading to the machining of larger or complicated workpieces and the use of expensive materials, the need for condition monitoring of cutting tools becomes increasingly evident. For these reasons, quality and productivity requirements through international competition have forced many manufacturers to use automated monitoring systems.

A variety of tool wear and failure sensing techniques have established the effectiveness of tool failure detection in the last few decades. Optical techniques have been used to measure the progress of tool wear by using a CCD camera [1] or a TV camera [2]. Uehara [3] detected tool wear by scanning chips with an electron microprobe analyser for wear debris removed from the cutting edge. Cook [4] used abraded radioactive wear particles; a small amount of radioactive material was implanted in the flank of the tool. The spot was checked at the end of every cutting cycle. If the spot disappeared, the spot would be considered to be tool worn. Gomayel [5] used an electromagnetic sensor to measure the change in diameter of a work piece and converted it to the size of wear on the tool. The voltage output obtained from the electromagnetic sensor was directly related to the gap between the sensor and the workpiece. Cutting forces have been used to relate to tool wear and tool breakage [6,7]. Sadat [8] detected flank wear by using the noise spectra resulting from the rubbing action of the tool with the workpiece. It was found that the noise in the frequency range $2.75-3.5 \mathrm{kHz}$ significantly increased from 9 to $24 \mathrm{~dB}$ as the tool became worn. Motor current [9] and motor power [10] of the spindle were investigated for tool wear and tool breakage sensing. Turkovich and Kramer [11], and Lin [12] attempted to 
measure the temperature in the cutting zone and relate it to tool wear. The temperature around the cutting tool edges was found to be related to wear, and the friction between the chip and the cutting tool. Takeyama [13] proposed that the slightest change of the cutting edge due to chipping or wear be detected using a pair of optical reflection systems. However, these techniques are not widely adopted in industry.

This paper described the development of a novel on-line tool wear condition monitoring intelligent system for single-point machining operations. This system used acoustic emission and vibration techniques for monitoring the different stages of tool wear. The root-mean-square value of the acoustic emission (AErms) and the coherence function between the acceleration signals at the tool tip in the tangential and feed directions were used to detect the progression of flank wear in carbide tool tips. An expert system, called the "Belief network" based on Bayes' rule, was utilised to integrate the information of AErms and vibration parameters for classifying the tool condition.

\section{THEORIES OF ACOUSTIC EMISSION AND COHERENCE FUNCTION FOR TOOL WEAR DETECTION}

\section{A. Acoustic emission and tool wear}

Acoustic emissions (AE), by definition, are transient elastic waves generated by the rapid release of energy from localised sources within a material [14]. These elastic waves can be detected by transducers attached to the surface of the specimen. Research into the use of acoustic emission for tool wear monitoring [15-19] has established that there exists a definite relation between AErms and tool wear.

AErms is the root mean square value of the AE signal. Since acoustic emission activity is attributed to the rapid release of energy in a material, the energy content of the acoustic emission signal can be related to this energy release. AErms can be defined as

$$
V_{r m s}=\left(\frac{1}{T} \int_{0}^{T} V^{2}(t) d t\right)^{\frac{1}{2}}
$$

where

$V(t) \quad=$ the voltage signal from an AE transducer, and

$T \quad=$ the duration of the signal.

\section{B. Coherence function and tool wear}

A cutting tool in turning is typically mounted as a cantilever. The cutting force can be represented by the three mutually perpendicular components, the radial, tangential and feed force components respectively along to as the $\mathrm{x}-, \mathrm{y}$ - and $\mathrm{z}$-axes. The radial force is relatively low compared to the other two and so the tool tip can be assumed to move mainly in the yz-plane. The shear force associated with the shear plane is resolvable into both the $\mathrm{y}$ - and z-directions, and thus the two component forces are correlated. On the other hand, the frictional forces that occur at the chip-tool and tool-workpiece interfaces are mainly forces confined in the respective $\mathrm{z}-$ and $\mathrm{y}-$ directions because of the geometry of the tool; these frictional forces are therefore largely uncorrelated.

The coherence function between the two acceleration signals is defined as

$$
\gamma^{2}=|G y z|^{2} / G y G z
$$

where $G y z$ is the cross spectrum between the acceleration signals in the tangential and feed directions; and $G y$ and $G z$ are the auto spectrum of the acceleration signals in the tangential and feed directions.

The meaning of the value of the coherence function can be divided into three cases:

- If the tangential force and feed force are completely uncorrelated so that $G_{Y Z}=0$, then $\gamma^{2}=0$

- If the tangential force and feed force are completely correlated, then $\gamma^{2}=1$

- In actual practice, since the two forces are never completely correlated nor uncorrelated, $0 \leq \gamma^{2} \leq 1$

\section{EXPERIMENTAL SET-UP AND RESULTS}

A tool holder (SDJCL 1616H 11) and carbide tool inserts (CG 4035 DCMT 11 T3 04-UF), both from Sandvick Coromant, were used. The insert geometry was: insert shape angle $55^{\circ}$, clearance angle $7^{\circ}$, rake angle $0^{\circ}$, cutting edge length $11 \mathrm{~mm}$, thickness $3.97 \mathrm{~mm}$ and nose radius 0.4 $\mathrm{mm}$.

An AE sensor (type WD from PAC) was mounted at the end of the tool-holder. Signals were amplified with a total gain of $34 \mathrm{~dB}$ band-passed filtered from $100 \mathrm{kHz}$ to 1 $\mathrm{MHz}$. The AE signal detected at the sensor was analysed in real time using a Hewlett Packard HP 89410A Vector Signal Analyser to produce a 401-line AErms spectrum spanning 0 to $1 \mathrm{MHz}$ and averaged over 250 consecutive spectra. The overall root mean square was calculated from overall the AErms spectrum.

Two accelerometers (model 303A03 from PCB) powered by a PCB power supply were mounted close to the tool tip: one in the direction of tangential force and the other in the direction of feed force. The measuring frequency ranges of the accelerometers are $1-10,000 \mathrm{~Hz}$ at $\pm 5 \%$ and 0.7 $20,000 \mathrm{~Hz}$ at $\pm 10 \%$. This model of accelerometer is designed for adhesive mounting. Because of the high temperature in cutting, glass-ceramic-disk insulators, 10 $\mathrm{mm}$ diameter by $1 \mathrm{~mm}$ thick, were attached between the tool holder and the accelerometers. A silicone rubber compound, which can withstand up to $250^{\circ} \mathrm{C}$, was used to 
mount both the accelerometers and glass-ceramic insulators. The outputs of the accelerometers were fed to the SI 1220 multi-channel spectrum analyser. 500 spectral points were recorded and analysed in the frequency range of $0 \mathrm{~Hz}-25 \mathrm{kHz}$ over 8 consecutive spectra.

Three sets of machining tests were conducted and their conditions are:

- Machining condition 1: Cutting speed, depth of cut and feed rate were constant at $150 \mathrm{~m} / \mathrm{min}, 1 \mathrm{~mm}$ and $0.3 \mathrm{~mm} / \mathrm{rev}$ respectively.

- Machining condition 2: Cutting speed, depth of cut and feed rate were constant at $250 \mathrm{~m} / \mathrm{min}, 0.75 \mathrm{~mm}$ and $0.25 \mathrm{~mm} / \mathrm{rev}$ respectively.

- Machining condition 3: Cutting speed, depth of cut and feed rate were constant at $300 \mathrm{~m} / \mathrm{min}, 0.5 \mathrm{~mm}$ and $0.2 \mathrm{~mm} / \mathrm{rev}$ respectively.

For all three machining conditions the wear curves show that flank wear increases approximately linearly with the cutting time as in Figs. 1, 2 and 3. The rapid flank wear is apparent at the final stage. The final flank wear length of the three cutting conditions before the onset of rapid wear rate are $0.44 \mathrm{~mm}$ at $40.9 \mathrm{~min}, 0.22 \mathrm{~mm}$ at $10.7 \mathrm{~min}$ and $0.28 \mathrm{~mm}$ at $19.9 \mathrm{~min}$ respectively.

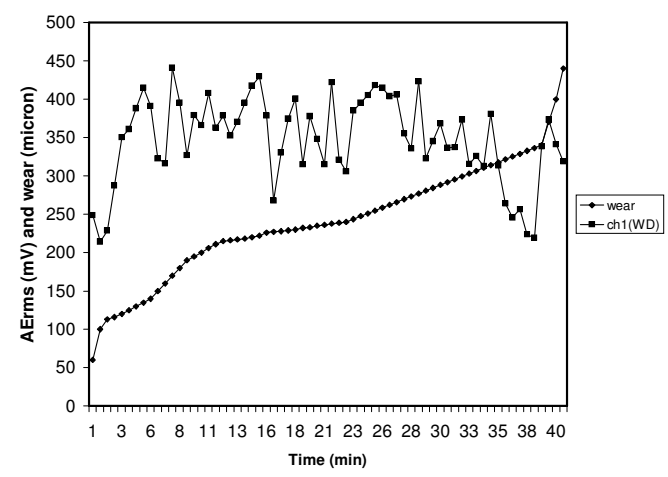

Fig 1. AErms obtained from machining test at speed 150 $\mathrm{m} / \mathrm{min}$, depth of cut $1.0 \mathrm{~mm}$ and feed rate $0.3 \mathrm{~mm} / \mathrm{rev}$.

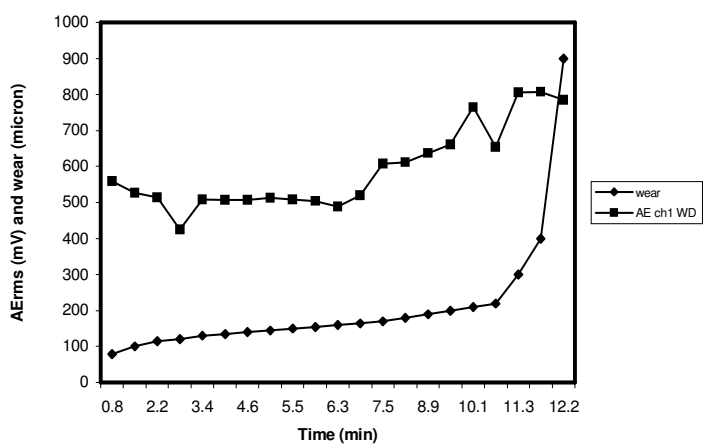

Fig 2. AErms obtained from machining test at speed 250 $\mathrm{m} / \mathrm{min}$, depth of cut $0.75 \mathrm{~mm}$ and feed rate $0.25 \mathrm{~mm} / \mathrm{rev}$.

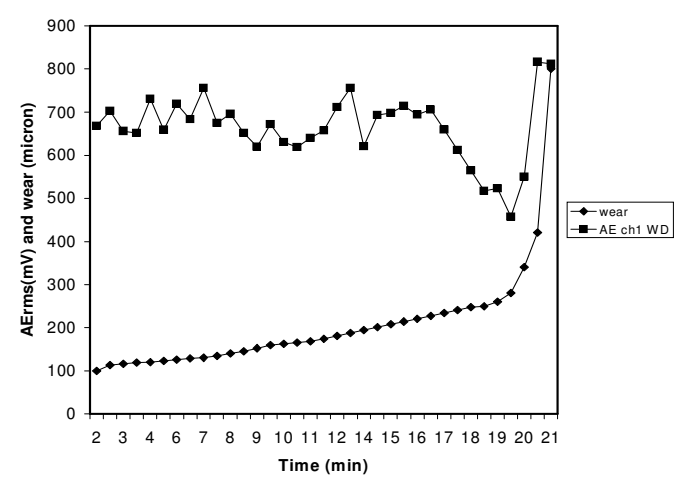

Fig 3. AErms obtained from machining test at speed 300 $\mathrm{m} / \mathrm{min}$, depth of cut $0.5 \mathrm{~mm}$ and feed rate $0.2 \mathrm{~mm} / \mathrm{rev}$.

For machining condition 1, AErms increased within the initial stage of wear and then settled down to a constant level with much local fluctuation. Machining condition 2 shows that during the second half stage the AErms increased with the progression of flank wear. Machining condition 3 shows that AErms was roughly constant with the progression of tool wear until the final stage when the AErms dropped before it rose again to the point when the tool was so worn that it could not be used.

Results of the coherence with tool wear show that the values of the coherence function in the vicinity of the natural frequency $(2.5 \mathrm{kHz}-5.5 \mathrm{kHz})$ decreased with tool wear whilst at the high frequency end $(18 \mathrm{kHz}-25 \mathrm{kHz})$ the coherence value increased. The relation of coherence function in the two frequency ranges, $2.5 \mathrm{kHz}-5.5 \mathrm{kHz}$ and $18 \mathrm{kHz}-25 \mathrm{kHz}$, with tool wear are demonstrated as in Figs 4, 5 and 6 for the three machining conditions.

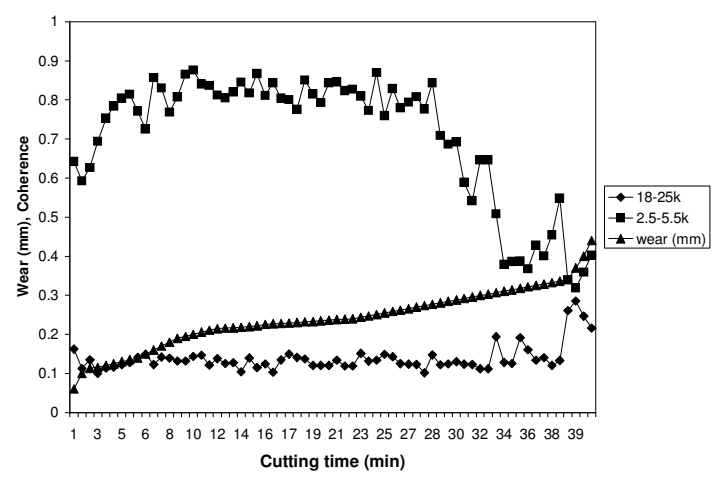

Fig 4. Coherence at frequency range $2.5-5.5 \mathrm{kHz}$ and $18-25$ $\mathrm{kHz}$ and flank wear with cutting time at cutting speed 150 $\mathrm{m} / \mathrm{min}$ depth of cut $1.0 \mathrm{~mm}$ and feed rate $0.3 \mathrm{~mm} / \mathrm{rev}$. 


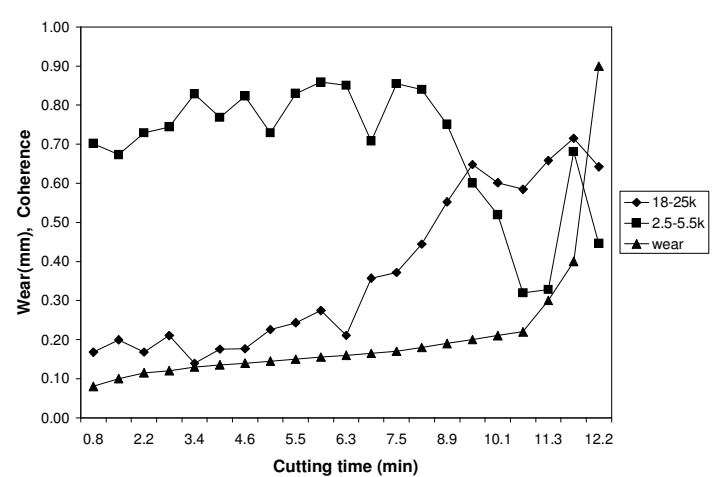

Fig 5. Coherence at frequency range $2.5-5.5 \mathrm{kHz}$ and $18-25$ $\mathrm{kHz}$ and flank wear with cutting time at cutting speed 250 $\mathrm{m} / \mathrm{min}$ depth of cut $0.75 \mathrm{~mm}$ and feed rate $0.25 \mathrm{~mm} / \mathrm{rev}$.

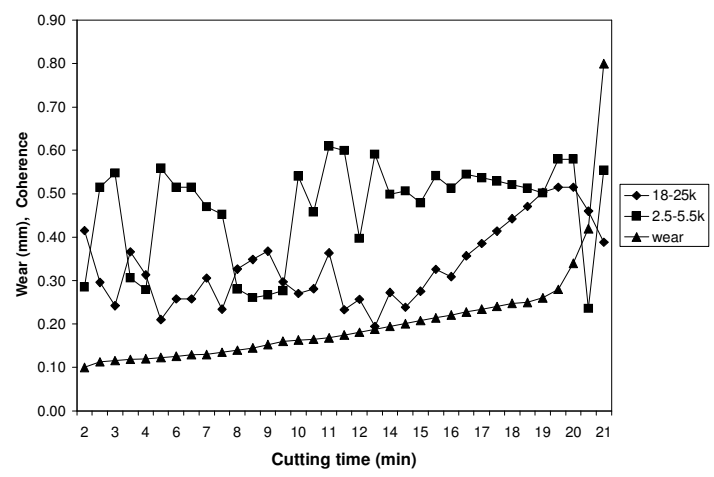

Fig 6. Coherence at frequency range $2.5-5.5 \mathrm{kHz}$ and $18-25$ $\mathrm{kHz}$ and flank wear with cutting time at cutting speed 300 $\mathrm{m} / \mathrm{min}$ depth of cut $0.5 \mathrm{~mm}$ and feed rate $0.2 \mathrm{~mm} / \mathrm{rev}$.

Forces acting on the tool tip can be considered to be made up of two parts: that which is correlated due to the common shear force and that which is uncorrelated due to friction at the two interfaces as explained in Section II.B. The tangential and feed forces in the respective $\mathrm{y}$ - and zdirections are partially correlated through the shear force. The friction forces at the chip/tool and tool/workpiece interfaces are uncorrelated forces appearing in the feed (z-) direction and tangential (y-) direction. These friction forces vary with the breaking of contacting asperities. At the advanced stage of wear the correlation represented by the coherence function at the natural frequency is much reduced because the frictional effect has become more dominant than that due to shear. Consequently, at around the resonance frequency of the tool, the coherence function falls with the progression of tool wear.

\section{BELIEF NETWORK}

In order to improve the robustness of the tool wear monitoring system, information from both the coherence function and AErms must be fully exploited. An expert system, named Netica, was used. The advantages of Netica are its ease of use, user-friendly graphical interface and low cost. Netica operates on the principle of "Bayes rule" which can be defined as

for $\mathrm{i}=1,2, \ldots . \mathrm{k}$

$$
P\left(S_{i} \backslash A\right)=\frac{P\left(A \backslash S_{i}\right) P\left(S_{i}\right)}{\sum_{j=1}^{k} P\left(A \backslash S_{j}\right) P\left(S_{j}\right)}
$$

where $\quad b(2 / \forall)=\quad$ posterior probability of $S i$ given

A.

$$
\mathrm{b}\left(\forall / \mathrm{Z}^{!}\right)=\quad \text { conditional probability of } A
$$

given $S i$

$$
\begin{array}{lll}
P\left(S_{i}\right) & = & \text { prior probability } \\
S_{2}, S_{3} \ldots . S_{k} & = & \text { a set of events. }
\end{array}
$$

In order to use belief networks, the distribution of conditional probability for each variable needs to be specified. In many applications, these probabilities are allocated by experts. In this paper the conditional probability was obtained from the case data contained in a file. This case file holds information of the coherence function in frequency ranges $2.5 \mathrm{kHz}-5.5 \mathrm{kHz}$ and $18 \mathrm{kHz}$ $-25 \mathrm{kHz}$, AErms, machining time and the stages of tool wear (worn and not worn).

The three features and machine time obtained from the three cutting conditions were used to train the network. The set of feature vectors for worn tools was divided into two equal sub-sets: one to train the network and the other to test it. It must be noted that the boundary between a worn and not-worn tool expressed in terms of the flank wear height was slightly different in the three machining conditions. The final flank wear height measured for the machining conditions 1,2 and 3 before the onset of rapid wear rate were $0.44 \mathrm{~mm}$ at $40.9 \mathrm{~min}, 0.22 \mathrm{~mm}$ at $10.7 \mathrm{~min}$ and $0.28 \mathrm{~mm}$ at $19.9 \mathrm{~min}$ respectively. Since the number of "worn" cases is small, they were used as a group to train the belief network.

Fig 7. shows the five nodes of the belief network referred to as 1) High_end, 2) Low_end, 3) AErms, 4) Machine_time and 5) Tool_wear nodes. The time range of the Machine_time node was divided into four sub-intervals taking into consideration the tool life of each cutting condition. The intervals, as shown in the first column in the Machine_time node in Figure 7, are 0-8 min, 8-16 min, 16$32 \mathrm{~min}$, and 32-45 min respectively. The second column of the Machine_time node indicates the probability values learnt from the case file. Similar to the Machine_time node, the ranges of AErms, High_end and Low_end nodes were divided into sub-ranges also based on the stages of tool wear, worn or not worn, for each machining condition. In the Tool_wear node, there are two stages: not_worn and worn. The probability of each stage was calculated using Equation 3. 


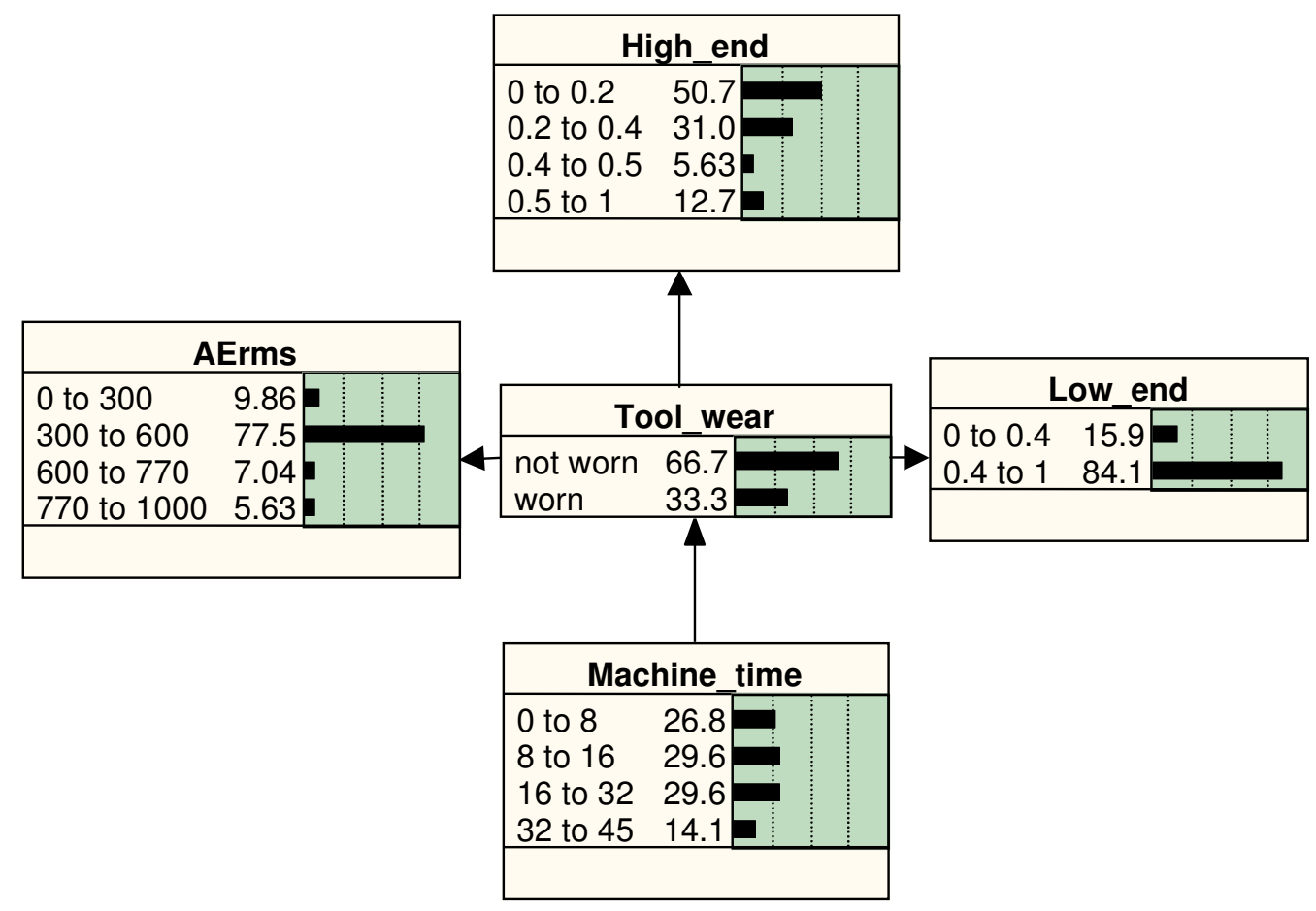

Fig 7. Belief network to predict the two stages of tool wear.

The numbers of cases used to train and test the network were 67 and 61 respectively. The predicted results of 61 cases were as shown in Table 1 below.

\begin{tabular}{|c|l|c|}
\hline \multicolumn{2}{|c|}{ Predicted } & Actual \\
\cline { 1 - 2 } not_worn & worn & \\
\hline 54 & 1 & not_worn $(55$ cases $)$ \\
\hline 1 & 5 & Worn 6 cases $)$ \\
\hline
\end{tabular}

Table 1. The predicted result of the belief network.

From Table 1, it can be seen that the misclassification error for the "not worn" status is $1 / 55=1.8 \%$ and the error for the "worn" status is $1 / 6=16.7 \%$. Taking the two statuses together, the total error rate of misclassification is $(1+1) /(55+6)=3.3 \%$. Although the missed detection of worn tool is relatively high, the monitoring can be made more robust by immediate sequential assessments. If the subsequent assessments return the same verdict, then the initial belief is reinforced.

\section{CONCLUSIONS}

Three cutting conditions were conducted on the EN24T workpiece material in a turning operation. The root-meansquare values of the $\mathrm{AE}$ (AErms) appear to be sensitive to tool wear and cutting condition.
At the advanced stage of tool wear, the values of the coherence function in the vicinity of the natural frequency $(2.5 \mathrm{kHz}-5.5 \mathrm{kHz})$ of the cutting tool decreased with tool wear because the frictional effects were more dominant than shear effects. Whilst in the high frequency range (18 $\mathrm{kHz}-25 \mathrm{kHz}$ ) the coherence function increased.

The belief network based on Bayes' rule was used to integrate information from $\mathrm{AE}$ and vibration in order to improve the correct recognition rate of the "worn" tool status. The three features and machining time obtained from the three cutting conditions were used to train and test the network. The overall success rate of the network in detecting a worn tool was high with an error rate of $3.3 \%$.

\section{ACKNOWLEDGMENTS}

The authors wish to acknowledge support from the Royal Thai Government and the INTErSECT Faraday Partnership, the Engineering and Physical Sciences Research Council.

\section{REFERENCES}

[1] R. Levi, A. Villa, G. Quaglia, R. Ghiara and G. Rutelli, An expert control system for tool life management in flexible manufacturing cells, Ann. CIRP 34, 87-90 (1985). 
[2] T. Sata, K. Matsushima and T. Kawabata, Recognition and control of the morphology of tool failures, Ann. CIRP 28, $43-47$ (1979).

[3] K. Uehara, On the mechanism of crater wear of carbide cutting tool, Ann. CIRP 21, 31-32 (1972).

[4] N.H. Cook, Tool wear sensors, Wear 62, 49-57 (1980).

[5] J.L.E. Gomayel and K.D. Bregger, On-line tool wear sensing for turning operations, J. Engng Ind. 108, 44-47 (1986).

[6] J. Tlusty and G.C. Andrews, A critical review of sensors for unmanned machining, Ann. CIRP 32, 536-572 (1983).

[7] M.S. Lan and D.A. Dornfeld, In-process tool fracture detection, J. Engng Mater. Technol. 106, 111-118 (1984).

[8] A. B. Sadat and S. Raman, Detection of tool flank wear using acoustic signature analysis, Wear 115, 265-272 (1987).

[9] Y. S. Liao, Development of a monitoring technique for tool change purpose in turning operations, Proc. 15th Int. Machine Tool Design and Research Conf. 251-257 (1974).

[10] N. Constantinides, S. Bennett, An investigation of methods for online estimation of tool wear, International Journal of Machine Tools and Manufacture 27 (2) (1987) 225-237.

[11] B.F. Turkovich and B.M. Kramer, A comprehensive tool wear model, Ann. CIRP 35, 67- 70 (1986).

[12] J. Lin, Inverse estimation of the tool-work interface temperature in end milling, International journal of Machine tool and Manufacture 35 (5) (1995) 751-760.
[13] H. Takeyama, H. Sekiguchi, R. Murata and H. Matsuzaki, In-process detection of surface roughness in machining, Ann. CIRP 25, 467-471 (1976)

[14] P. Mclntire (1987), "Nondestructive Testing Handbook Second Edition" Volume 5 Acoustic Emission Testing, American Society for Nondestructive Testing.

[15] E.N.Diei and D.A.Dornfeld, "A model of tool fracture generated acoustic emission during machining", Trans.ASME, Journal of Engineering for Industry, 109 (3) (1989) 229-237.

[16] E. Kannatey-Asibu, Jr. and D.A.Dornfeld, "Quantitative relationships for acoustic emission from orthogonal metal cutting", Trans.ASME, Journal of Engineering for Industry, 103 (3) (1981) 330-340.

[17] L. Dan and J.Mathew, "Tool wear and failure monitoring techniques for turning-a review", 1st J.Mach. Toos Manufact, 30 (4) (1990) 579-598.

[18] R.Teti and D.A. Dornfeld, "Modelling and experimental analysis of acoustic emission from metal cutting", Trans. ASME, Journal of Engineering for Industry, 111(3) (1989) 229-237.

[19] M.S. Lan and D.A Dornfeld, "In-process tool fracture detection", Journal of Engineering Materials and Technology, 106 (2) (1984) 111118. 